US Army Corps

of Engineers ${ }_{\circledast}$

Engineer Research and

Development Center

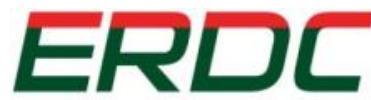

INNOVATIVE SOLUTIONS

for a safer, better world

ERDC 6.2 Advanced Low Logistics Water (ALL-H2O)

\title{
Surface Wettability Using Contact Angle Goniometry
}

Jack Heller and Emily Asenath-Smith

February 2018

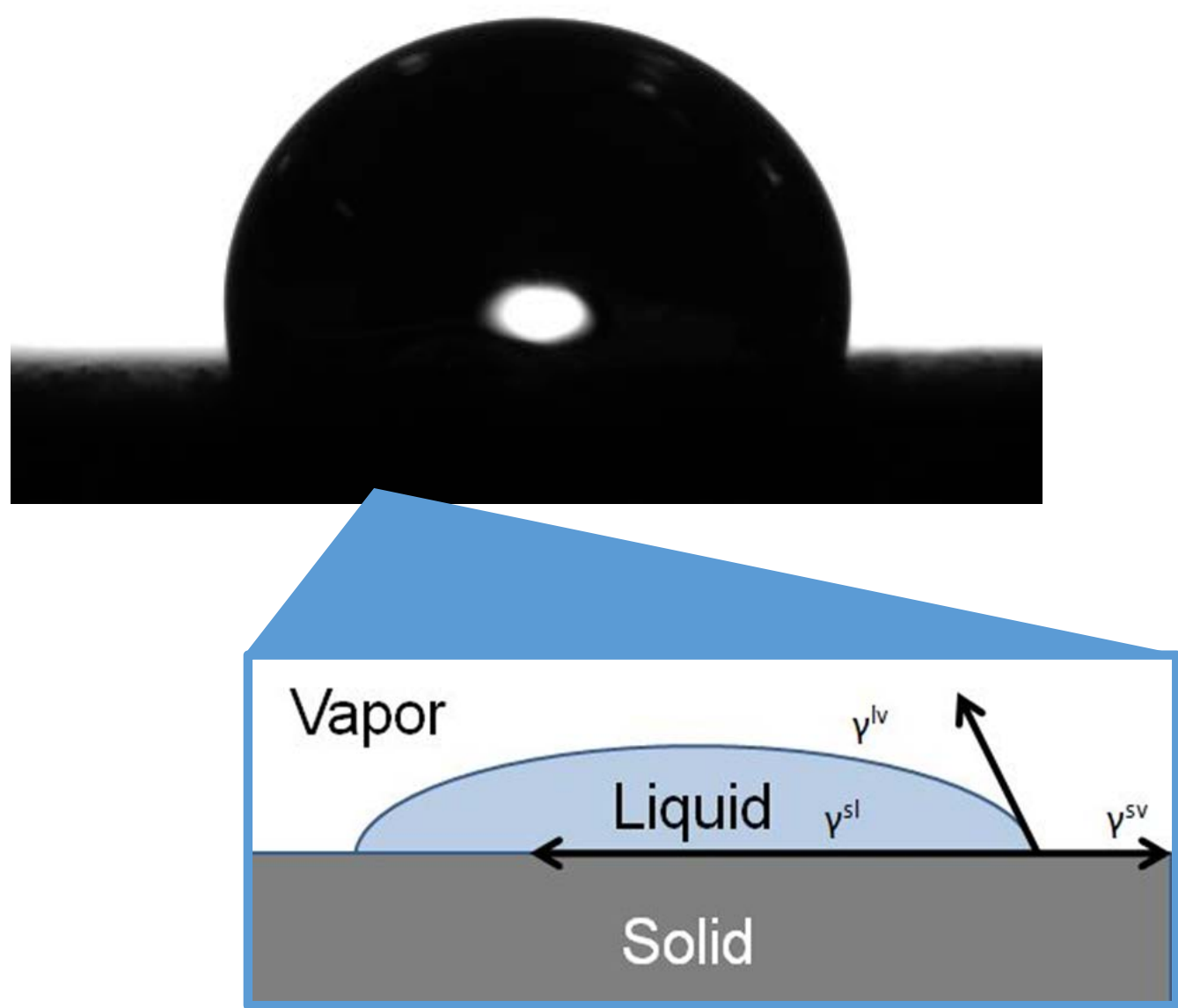


The U.S. Army Engineer Research and Development Center (ERDC) solves the nation's toughest engineering and environmental challenges. ERDC develops innovative solutions in civil and military engineering, geospatial sciences, water resources, and environmental sciences for the Army, the Department of Defense, civilian agencies, and our nation's public good. Find out more at www.erdc.usace.army.mil.

To search for other technical reports published by ERDC, visit the ERDC online library at http://acwc.sdp.sirsi.net/client/default. 


\section{Surface Wettability Using Contact Angle Goniometry}

Jack Heller and Emily Asenath-Smith

U.S. Army Engineer Research and Development Center (ERDC)

Cold Regions Research and Engineering Laboratory (CRREL)

72 Lyme Road

Hanover, NH 03755-1290

Final Report

Approved for public release; distribution is unlimited.

Prepared for Assistant Secretary of the Army for Acquisition, Logistics and Technology 103 Army Pentagon

Washington, DC 20314-1000

Under ERDC 6.2 Advanced Low Logistics Water (ALL-H2O), "Task 9: Watershed Coatings," Program Element 622720048, "Industrial Operations Pollution Control Guidance" 


\section{Abstract}

This study measured surface wettability on a variety of coatings at various temperatures to assess the capacity of the coatings to facilitate water condensation for water collection from vapor. Both commercial polymeric coatings and oxide coatings made in house were selected based on their published hydrophobicity, and aluminum and copper coupons were used as substrates. Dynamic contact angle measurements were performed over the temperature range $5^{\circ} \mathrm{C}-50^{\circ} \mathrm{C}$ with an automated, tilting-stage, contact angle goniometer equipped with a Peltier environmental chamber for temperature control. While the commercial polymeric coatings exhibited consistent (super) hydrophobic wettability across all substrates, the roll-off angles were greater than 20 degrees. The most promising candidate was the wet-oxide coating formed on copper substrates. The high contact angles, low hysteresis, and negligible roll-off angles imply that droplets formed on these surfaces would have very low adhesion and high collection efficiency.

DISCLAIMER: The contents of this report are not to be used for advertising, publication, or promotional purposes. Citation of trade names does not constitute an official endorsement or approval of the use of such commercial products. All product names and trademarks cited are the property of their respective owners. The findings of this report are not to be construed as an official Department of the Army position unless so designated by other authorized documents. 


\section{Contents}

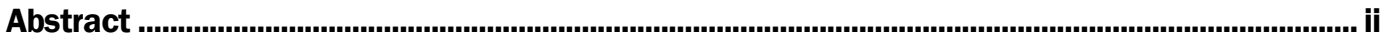

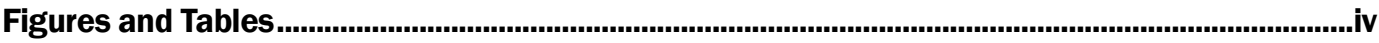

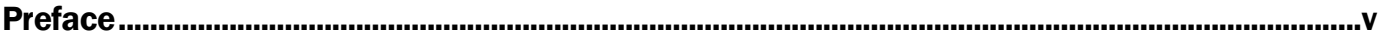

1 Introduction ............................................................................................................................. 1

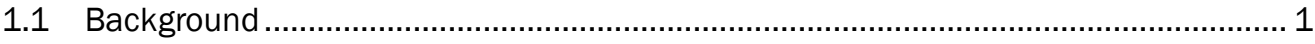

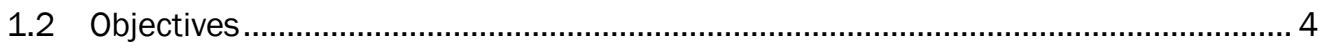

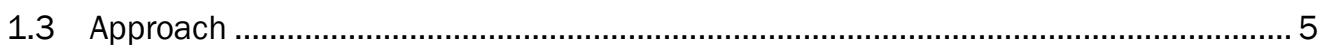

2 Methods ........................................................................................................................................6 6

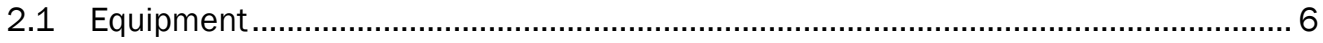

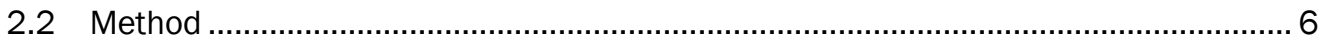

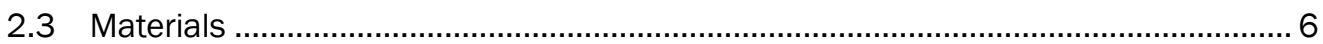

3 Results ........................................................................................................................................ 8

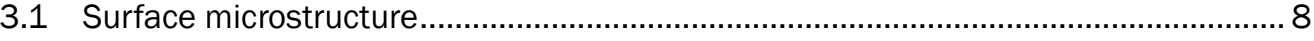

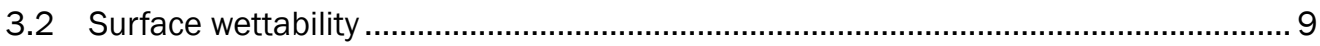

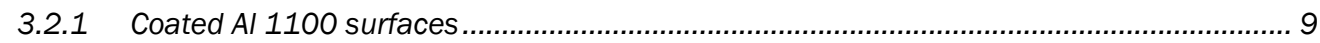

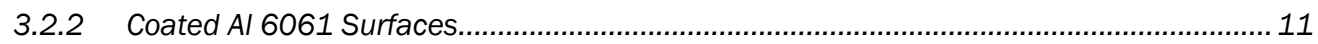

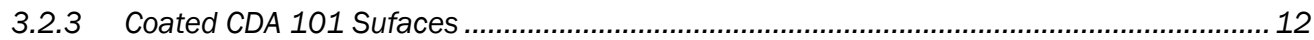

4 Discussion .....................................................................................................................................14

5 Conclusion .................................................................................................................................16

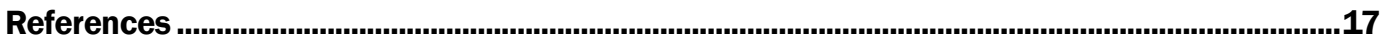

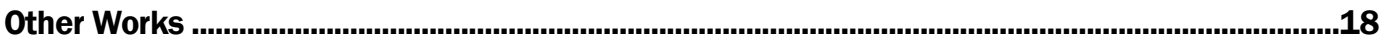

Appendix A: Standard Operating Procedure for Temperature-Variable Contact Angle

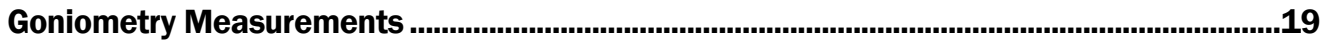

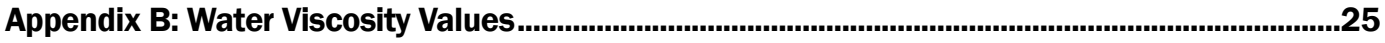

\section{Report Documentation Page}




\section{Figures and Tables}

\section{Figures}

1 A graphical illustration of the static contact angle of a liquid and the force vectors at the three-phase boundary line that are related to the contact angle via Young's Equation. The angle is static because it is taken on a stationary droplet that is positioned on a level surface

2 A graphical illustration of dynamic contact angles and their measurement. Angle $a$ is the advancing contact angle, and angle $r$ is the receding contact angle. 3

3 A graphical illustration of the Cassie-Baxter and the Wenzel models for a droplet on a textured surface. In the Cassie-Baxter model, the droplet sits on asperities in the surface, minimizing interfacial contact area and reducing droplet adhesion. In the Wenzel state, the droplet makes complete contact with the material surface, with increased interfacial contact area, creating high adhesion.

4 Roughness and morphology characterization of copper metal coupons (control) (left) and copper oxide coating on a copper metal coupon (right)

5 A graph of the root mean square roughness of the different coatings on the metal substrates. (The data was derived from laser scanning confocal microscopy image analysis performed at ERDC-CERL.)

6 Advancing, receding, and roll-off angles of coatings on an Al 1100 substrate: (a) Al 1100 with no coating applied, (b) Al 1100 with a SuperCN coating applied, (c) Al 1100 with a SuperCN+ coating, and (d) Al 1100 with a wet-oxide coating applied. Note: droplets did not roll from surfaces $a$ and $d$ during tilting experiments

7 Advancing, receding, and roll-off angles of coatings with an Al 6061 substrate:

(a) Al 6061 with no coating applied, (b) Al 6061 with a SuperCN coating applied, (c) Al 6061 with a SuperCN+ coating, and (d) Al 6061 with a wet-oxide coating applied. Note: droplets did not roll from the bare coupons (a) during tilting experiments.

8 Advancing, receding, and roll-off angles of coatings with a CDA 101 substrate: (a) CDA 101 with no coating applied, (b) CDA 101 with a SuperCN coating applied, (c) CDA 101 with a SuperCN+ coating, and (d) CDA 101 with a wet-oxide coating applied. Note: droplets did not roll from the bare coupons (a) during tilting experiments.

\section{Tables}

1 Technical characteristics of the Ramé-Hart Model 590 Contact Angle Goniometer.

2 Summary of materials tested in this research .................................................................

B-1 Water viscosity values as a function of temperature. 


\section{Preface}

This study was conducted for the Assistant Secretary of the Army for Acquisition, Logistics and Technology under U.S. Army Engineer Research and Development Center (ERDC) 6.2 Advanced Low Logistics Water (ALL-H2O), "Task 9: Watershed Coatings." The technical monitor was Mr. Kurt Kinnevan, Office of the Technical Directors, Environmental Quality and Installations.

The work was performed by the Force Projection and Sustainment Branch (CEERD-RRH) of the Research and Engineering Division (CEERD-RR), ERDC Cold Regions Research and Engineering Laboratory (ERDCCRREL). At the time of publication, Ms. Erin Bodie was Chief, CEERDRRH, and CDR J. D. Horne, USN (Ret) was Chief, CEERD-RR. The Deputy Director of ERDC-CRREL was Dr. Lance Hansen, and the Director was Dr. Joseph L. Corriveau.

We are grateful to the Task 9 team members who made this work possible. In particular, we appreciate the surface characterization (Figures 4 and 5) provided by Mr. Ben Masters.

COL Bryan S. Green was Commander of ERDC, and Dr. David W. Pittman was the Director. 



\section{Introduction}

\subsection{Background}

Many biological organisms present chemically and structurally sophisticated models for manipulating the flow of water; some repel the adherence of droplets while others attract water from the air. In particular, lotus leaves resist the adhesion of water droplets owing to the hierarchical surface structure and chemical composition present at their surfaces (Shin et al. 2016). On the other end of the spectrum, desert beetles collect water from the air using chemical patterning and surface roughness on their backs (Parker and Lawrence 2001). Such examples present models for self-cleaning surfaces and water harvesting from the atmosphere, respectively. The fundamental design motif being engineered surface wettability, which stems from physical structure and chemical functionality.

Surface wettability is a simple and elegant method to measure interfacial energies between solid, liquid, and vapor phases by simply studying the response of a water droplet to a surface of interest. The measured energies are a result of physical structure and chemical functionality and indicate the function and reliability of materials and surfaces for a range of applications, including manufacturing processes, advanced materials, and energy industries. One application of wettability studies is in advanced coatings for water condensation (Lee et al. 2012). Similar to the desert beetles, the ability to condense water droplets from vapor and direct their flow for collection depends on the wettability of the surfaces involved (Ashokkumar et al. 2012).

To measure surface wettability, a droplet of known volume is dispensed onto a surface; and the angle at the three-phase (solid, liquid, and vapor) contact line (Figure 1) is measured with a contact angle goniometer. The angle measured, known as the contact angle $(\theta)$, depends on the surface tension of the liquid $\left(\gamma^{l v}\right)$, the interfacial tension between the liquid and the solid $\left(\gamma^{s l}\right)$, and the surface free energy of the solid $\left(\gamma^{s v}\right)$. Surfaces on which water spreads easily are referred to as hydrophilic; those that repel water are known as hydrophobic. As a macroscale measurement, the contact angle is a quantitative measure of molecular-scale interactions at the three-phase boundary. The relationship between all these quantities is expressed in Young's equation (Equation 1): 


$$
\gamma_{s v}=\gamma_{s l}+\gamma_{l v} \cos \theta
$$

Generally, surfaces on which water spreads easily $(\theta<90$ degrees $)$ are hydrophilic; those that repel water $(\theta>90$ degrees $)$ are hydrophobic. As a macroscale measurement, the contact angle is a measure of molecularscale interactions at the three-phase boundary resulting from physical structure and chemical functionality of the surfaces.

Figure 1. A graphical illustration of the static contact angle of a liquid and the force vectors at the three-phase boundary line that are related to the contact angle via Young's Equation. The angle is static because it is taken on a stationary droplet that is positioned on a level surface.

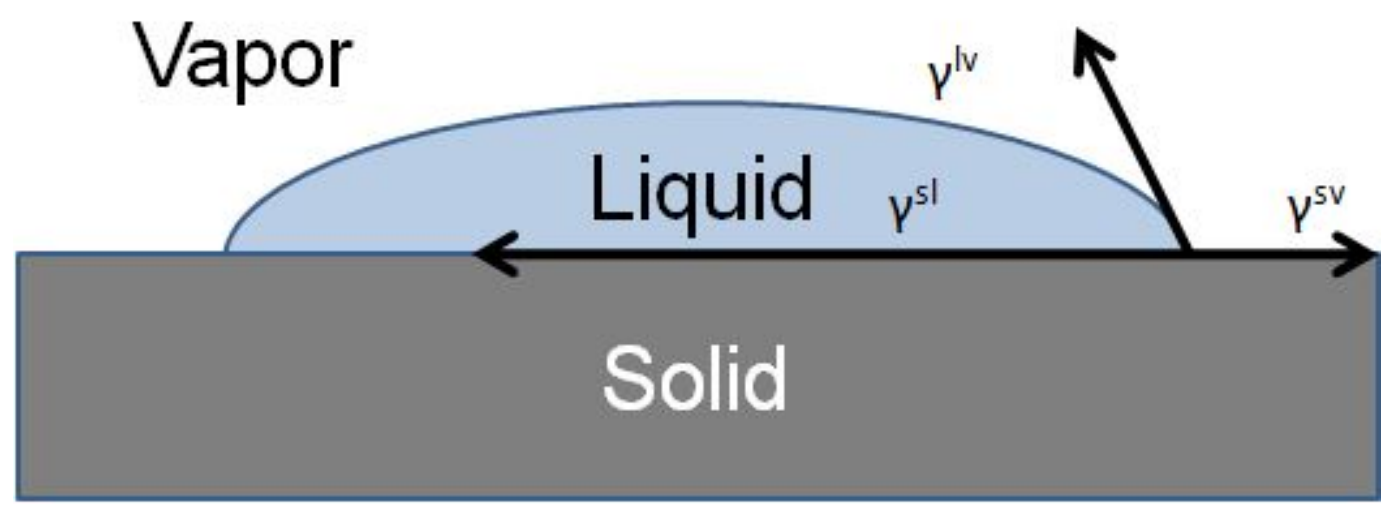

Contact angle can be measured statically or dynamically. The static contact angle measurement yields one value that corresponds to the state of a droplet at rest on the surface of interest. Dynamic contact angle measurement involves measuring the angle at the three-phase boundary while the volume of the droplet is changing. Thus, dynamic measurements produce two contact angle values: the advancing angle $\left(\theta_{A}\right)$, which is taken during droplet expansion, and the receding angle $\left(\theta_{R}\right)$, which is found while the droplet is contracting. Modern instrumentation has brought automation to dynamic measurements, allowing them to be performed by stage tilting rather than by droplet addition/withdrawal. Using a tilting base, the advancing angle is found from the leading edge of the droplet, and the receding angle is found from the retreating side of the droplet (Figure 2). 
Figure 2. A graphical illustration of dynamic contact angles and their measurement. Angle $a$ is the advancing contact angle, and angle $r$ is the receding contact angle.

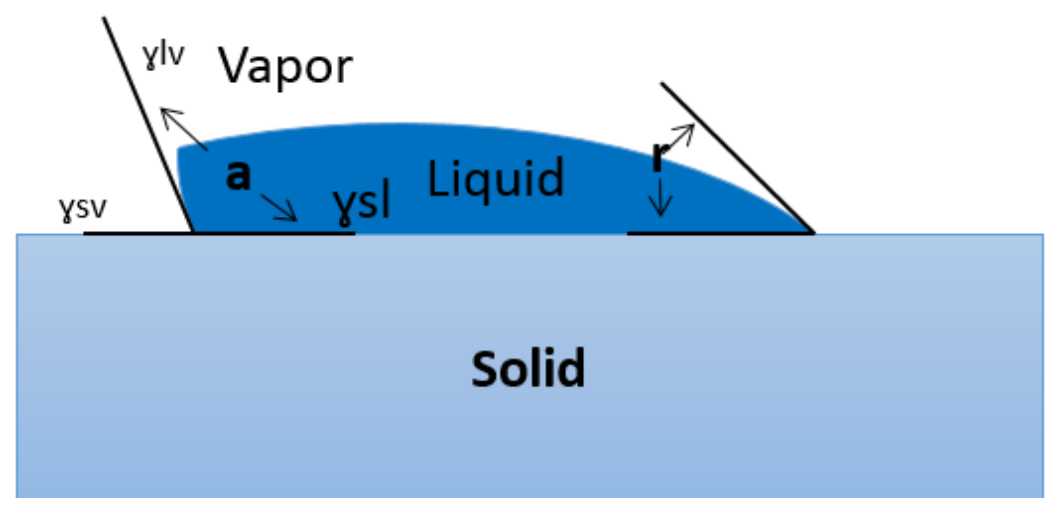

The two angles found from dynamic contact angle measurement provide further information on the surface chemistry and physical structure of surfaces and are necessary values for a full characterization of surface wettability (Gao and McCarthy 2008). Known as the contact angle hysteresis, the difference between the advancing and receding angles is caused by physical texture of the surface and the maximum and minimum stable contact angles for that scenario (Cheng et al. 2016). A high hysteresis implies a rough surface to which the liquid can adhere.

Droplet adhesion to rough surfaces is dictated by the interfacial contact area and the energy barrier associated with the wetting process Murakami et al. 2014. As described by the Cassie-Baxter and Wenzel models for surface wettability (Figure 3), a water droplet suspended above surface asperities will trap air pockets below it, reducing the interfacial surface area. This metastable state creates an environment with low adhesion, allowing the water droplet to roll off at low angles. A water droplet that penetrates surface asperities will create additional surface area between the droplet and the coating, allowing it to have higher adhesion and a higher roll-off angle. Both types of surfaces may have high contact angle values, but the hysteresis will be greater in the Wenzel state. 
Figure 3. A graphical illustration of the Cassie-Baxter and the Wenzel models for a droplet on a textured surface. In the Cassie-Baxter model, the droplet sits on asperities in the surface, minimizing interfacial contact area and reducing droplet adhesion. In the Wenzel state, the droplet makes complete contact with the material surface, with increased interfacial contact area, creating high adhesion.

Cassie-Baxter

State

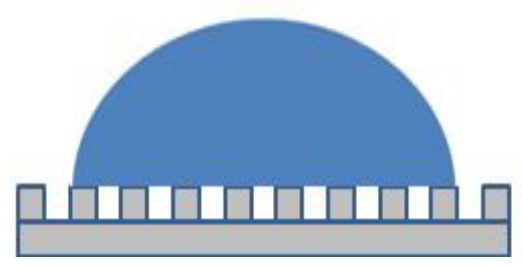

Wenzel

State

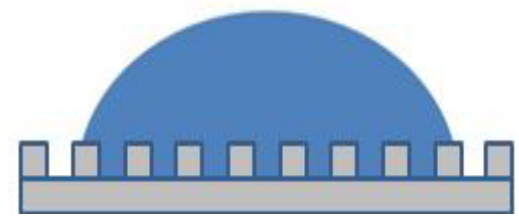

The adhesion of a droplet to a surface is measured by tilting the stage until the droplet rolls away. This roll-off angle indicates how much surface friction exists between the droplet and the solid. A high roll-off angle characterizes high surface friction and droplet adhesion, and a low roll-off angle indicates a low surface friction and droplet adhesion. Roll-off angle is a helpful measurement when looking for a good water-repellent surface or a surface for water collection. For example, a condensation coating needs both a high contact angle and a low roll-off angle to shed condensed water droplets and to allow them to roll with ease for collection.

\subsection{Objectives}

The U.S. Army Engineer Research and Development Center (ERDC) was interested in exploring the application of various coating materials for water harvesting. Various hydrophobic coatings were sourced, applied to metal coupons, and imaged by the Construction Engineering Research Laboratory (CERL) in Champaign, Illinois. Surface wettability studies were performed on the coated coupons at the Cold Regions Research and Engineering Laboratory (CRREL) in Hanover, New Hampshire. To study the effectiveness of the coatings for water harvesting, coated coupons were subject to condensation studies at the Environmental Laboratory (EL) in Vicksburg, Mississippi. By studying a variety of coatings, we sought to identify a connection between surface structure and chemistry with surface wettability and water collection efficiency. 
This report is primarily a summary of the surface wettability studies performed at CRREL. The goal of these studies was to see if there was a correlation between temperature, contact angle, and roll-off angle, as in practice, condensation systems will operate on thermal gradients. We sought to investigate the temperature dependence of contact angle, hysteresis, and roll-off angle to the selected coatings. In particular, we investigated the hypothesis that surfaces with high contact angles and low roll-off angles would be associated with increased rates of water condensation.

\subsection{Approach}

We used a tilting-base contact angle goniometer equipped with a Peltier environmental chamber to simultaneously measure dynamic contact angles and roll-off angle on a variety of coated surfaces over the temperature range of $5{ }^{\circ} \mathrm{C}-50^{\circ} \mathrm{C}$. With this approach, we sought to identify trends in contact angle and roll-off angle as a function of temperature so that we could make predictions and comparisons to the efficacy of the surfaces in water condensation applications. 


\section{Methods}

\subsection{Equipment}

Testing used a Ramé-Hart Model 590 contact angle goniometer equipped with a tilting base capable of achieving angles from o to 180 degrees. The system was also equipped with an automated dispensing system (Model 100-25-A) and a Peltier environmental chamber (Model 100-30) with a temperature range from $-50^{\circ} \mathrm{C}$ to $150^{\circ} \mathrm{C}$. The technical specifications of the components are compiled in Table 1.

Table 1. Technical characteristics of the Ramé-Hart Model 590 Contact Angle Goniometer.

\begin{tabular}{|c|c|c|c|c|c|c|}
\hline $\begin{array}{c}\text { Tilting Base } \\
\text { Resolution }\end{array}$ & $\begin{array}{c}\text { Liquid Output } \\
\text { Accuracy }\end{array}$ & $\begin{array}{c}\text { Liquid } \\
\text { Output } \\
\text { Resolution }\end{array}$ & $\begin{array}{c}\text { Contact } \\
\text { Angle } \\
\text { Range }\end{array}$ & $\begin{array}{c}\text { Contact } \\
\text { Angle } \\
\text { Resolution }\end{array}$ & $\begin{array}{c}\text { Contact } \\
\text { Angle } \\
\text { Accuracy }\end{array}$ & $\begin{array}{c}\text { Temperature } \\
\text { Precision }\end{array}$ \\
\hline $0.1^{\circ}$ & $+/-0.002 \mu \mathrm{L}$ & $0.01 \mu \mathrm{L}$ & $0^{\circ}-180^{\circ}$ & $0.01^{\circ}$ & $+/-0.10^{\circ}$ & $0.10^{\circ} \mathrm{C}$ \\
\hline
\end{tabular}

\subsection{Method}

After temperature equilibration at the desired set point for 20 mins, the automated dispenser was used to deposit a $10 \mu \mathrm{L}$ drop onto the coated coupon of interest. Dynamic contact angles and roll-off angle were measured simultaneously during stage tilting from o to 90 degrees. The system was set to tilt at a rate of 1 degree per second. To combat condensation within the environmental chamber, dry air was pumped into the Peltier environmental chamber for the experiments conducted at $5^{\circ} \mathrm{C}$.

For a full standard operating procedure, see Appendix A. The droplet characteristics and stage tilt were analyzed using DROPimage software (RameHart). Five replicates of each condition were performed; the reported values are the average and standard deviation.

\subsection{Materials}

The ERDC team selected the coatings used in this research from the class of hydrophobic materials with variable roughness and chemistry. Two polymeric condensation coatings were commercially sourced (Nanomyte ${ }^{\circledR}$ SuperCN and SuperCN Plus, NEI Corporation) and applied to the metal coupons at CERL. Wet oxide coatings based on copper oxide and aluminum oxide were formed directly on the parent metal coupons by using an 
in-house process at CERL. This process uses an aqueous immersion protocol that forms superhydrophobic coatings composed of the metal oxide of the coupon material. Because these coatings are compositionally hydrophilic, their hydrophobicity is a result of physical structure alone (Li et al. 2011). The coatings were applied to both aluminum ( $\mathrm{Al} 1100$ and $\mathrm{Al} 6061$ alloys) and copper (CDA 101) coupons (McMaster-Carr). All coupons were 1200 grit roughness. Table 2 summarizes the materials.

Table 2. Summary of materials tested in this research

\begin{tabular}{|c|c|c|c|}
\hline Name & Coating Type & Substrate & Coating Source \\
\hline A1CNTRL & $\mathrm{n} / \mathrm{a}$ & Al 1100 & $\mathrm{n} / \mathrm{a}$ \\
\hline A6CNTRL & $\mathrm{n} / \mathrm{a}$ & Al 6061 & $\mathrm{n} / \mathrm{a}$ \\
\hline C1CNTRL & $\mathrm{n} / \mathrm{a}$ & CDA 101 & $\mathrm{n} / \mathrm{a}$ \\
\hline A1SCN & Polymeric & Al 1100 & NEI Corp. \\
\hline A6SCN & Polymeric & Al 6061 & NEI Corp. \\
\hline C1SCN & Polymeric & CDA 101 & NEI Corp. \\
\hline A1SCNP & Polymeric & Al 1100 & NEI Corp. \\
\hline A6SCNP & Polymeric & Al 6061 & NEI Corp. \\
\hline C1SCNP & Polymeric & CDA 101 & NEI Corp. \\
\hline A1Wo & Oxide & Al 1100 & In-House \\
\hline A6WO & Oxide & Al 6061 & In-House \\
\hline C1W0 & Oxide & CDA 101 & In-House \\
\hline
\end{tabular}




\section{Results}

The coating materials chosen for this study had hydrophobic characteristics stemming from different origins: the polymeric coatings have both hydrophobic composition and physical roughness; the oxide coatings have hydrophilic composition but high physical roughness, which imparts (super) hydrophobicity. These different materials were chosen to allow us to consider chemical and structural differences in the surface wettability properties. We performed dynamic contact angle goniometer measurements on the materials at $5^{\circ} \mathrm{C}, 25^{\circ} \mathrm{C}, 35^{\circ} \mathrm{C}$, and $50^{\circ} \mathrm{C}$, allowing us to measure advancing and receding contact angles and roll-off angle as a function of temperature.

\subsection{Surface microstructure}

The CERL team used both laser-scanning optical microscopy and scanning electron microscopy to characterize the roughness and morphology of the surfaces and coating materials. Figure 4 shows an example of this imaging. A quantitative measure of the surface roughness of each metal and coating was extracted from the optical microscopy image data. The root mean squared roughness is compiled in Figure 5. These results demonstrate that the polymeric SuperCN coating is quite smooth as it retains the roughness of the parent metal coupons. Thus, these coatings would be hydrophobic as a result of composition or chemistry of the materials. Conversely, the oxide coatings show a much greater variation in the roughness values, implying they are rougher than the metal coupons, achieving hydrophobicity from physical structure.

Figure 4. Roughness and morphology characterization of copper metal coupons (control) (left) and copper oxide coating on a copper metal coupon (right).
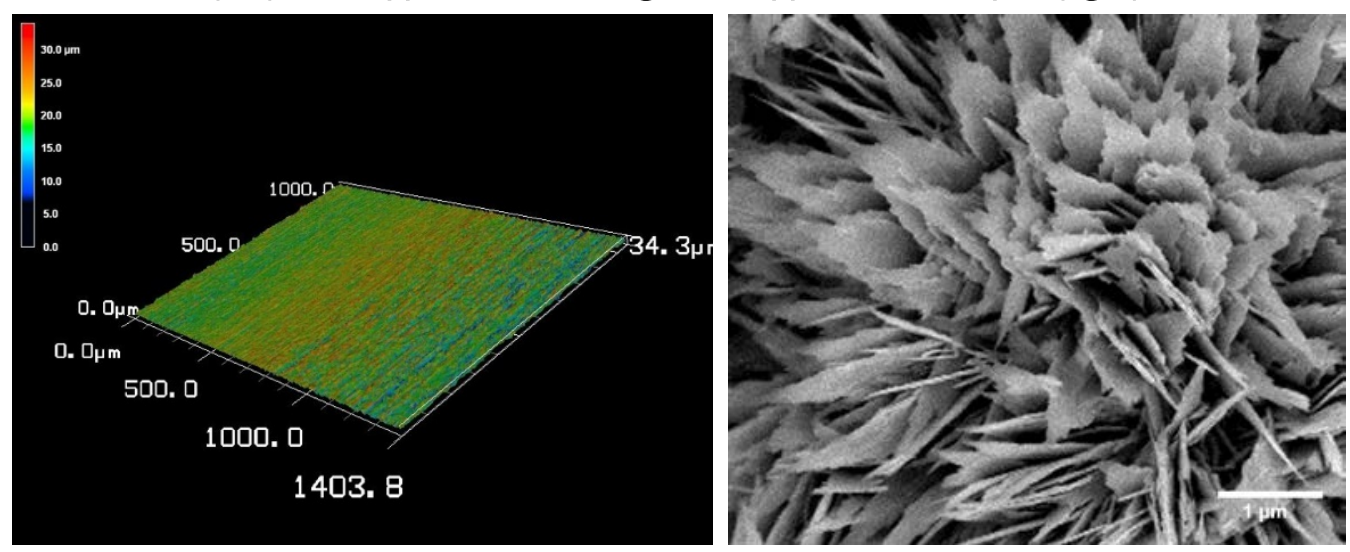
Figure 5. A graph of the root mean square roughness of the different coatings on the metal substrates. (The data was derived from laser scanning confocal microscopy image analysis performed at ERDC-CERL.)

Root Mean Square Roughness - $\mathrm{R}_{\mathrm{q}}$

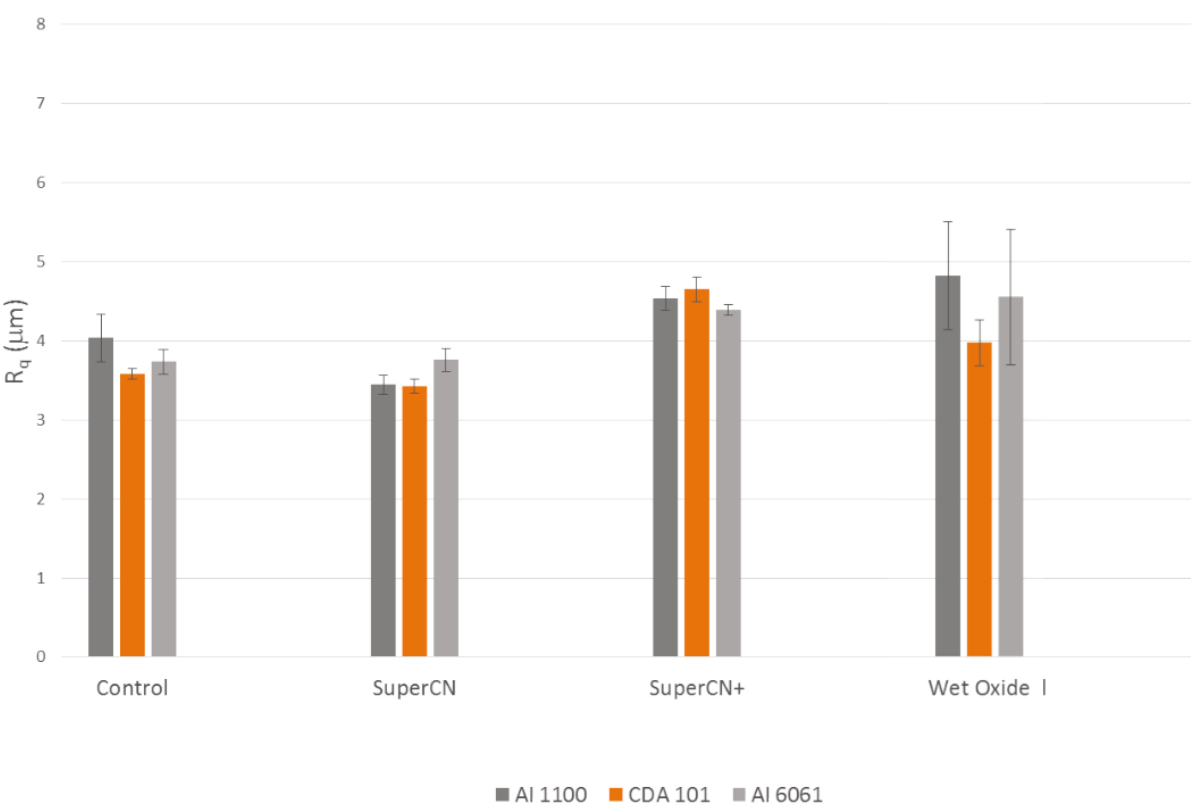

\subsection{Surface wettability}

We examined the wettability of the different coatings on each metal substrate. In particular, we measured the temperature dependence of the advancing contact angle, receding contact angle, and the roll-off angle.

\subsubsection{Coated Al 1100 surfaces}

The $\mathrm{Al} 1100$ control coupons had advancing and receding contact angles that remained fairly constant at 85 and 60 degrees, respectively, as temperature varied (Figure 6a). Even upon tilting to fully vertical $\left(90^{\circ}\right)$, the droplets did not roll off the uncoated (control) surfaces.

The SuperCN coated surfaces had higher contact angles (advancing was approximately 120 degrees, and the receding was approximately 100 degrees) (Figure 6b) as compared to the controls. As with the controls, the advancing and receding angles of SuperCN were constant with temperature. The droplets on SuperCN surfaces did roll off at low angles (between 20 and 40 degrees). 
The highest contact angles were measured on the SuperCN Plus coated surfaces (Figure 6c). While the advancing angle was constant around 160 degrees regardless of temperature, the receding angle dropped sharply from 130 to 100 degrees as temperature decreased from $25^{\circ} \mathrm{C}$ to $5^{\circ} \mathrm{C}$. The roll-off angle also showed a change in trend between $25^{\circ} \mathrm{C}$ and $5^{\circ} \mathrm{C}$, increasing from 20 to 60 degrees, implying that the surface interactions had become more adhesive.

Despite having a hydrophilic composition, the wet-oxide coating on the $\mathrm{Al}$ 1100 substrate, had hydrophobic advancing and receding contact angles of 120 and 80 degrees, respectively, which also remained constant as a function of temperature (Figure 6d). The droplets remained adhered to the coating throughout tilting. The large hysteresis ( $\sim 40$ degrees) coupled with the greater standard deviation of the contact angle values is consistent with a coating that achieves hydrophobicity because of physical structure.

Figure 6. Advancing, receding, and roll-off angles of coatings on an Al 1100 substrate: (a) Al 1100 with no coating applied, (b) Al 1100 with a SuperCN coating applied, (c) Al 1100 with a SuperCN+ coating, and (d) Al 1100 with a wet-oxide coating applied. Note: droplets did not roll from surfaces $a$ and $d$ during tilting experiments.

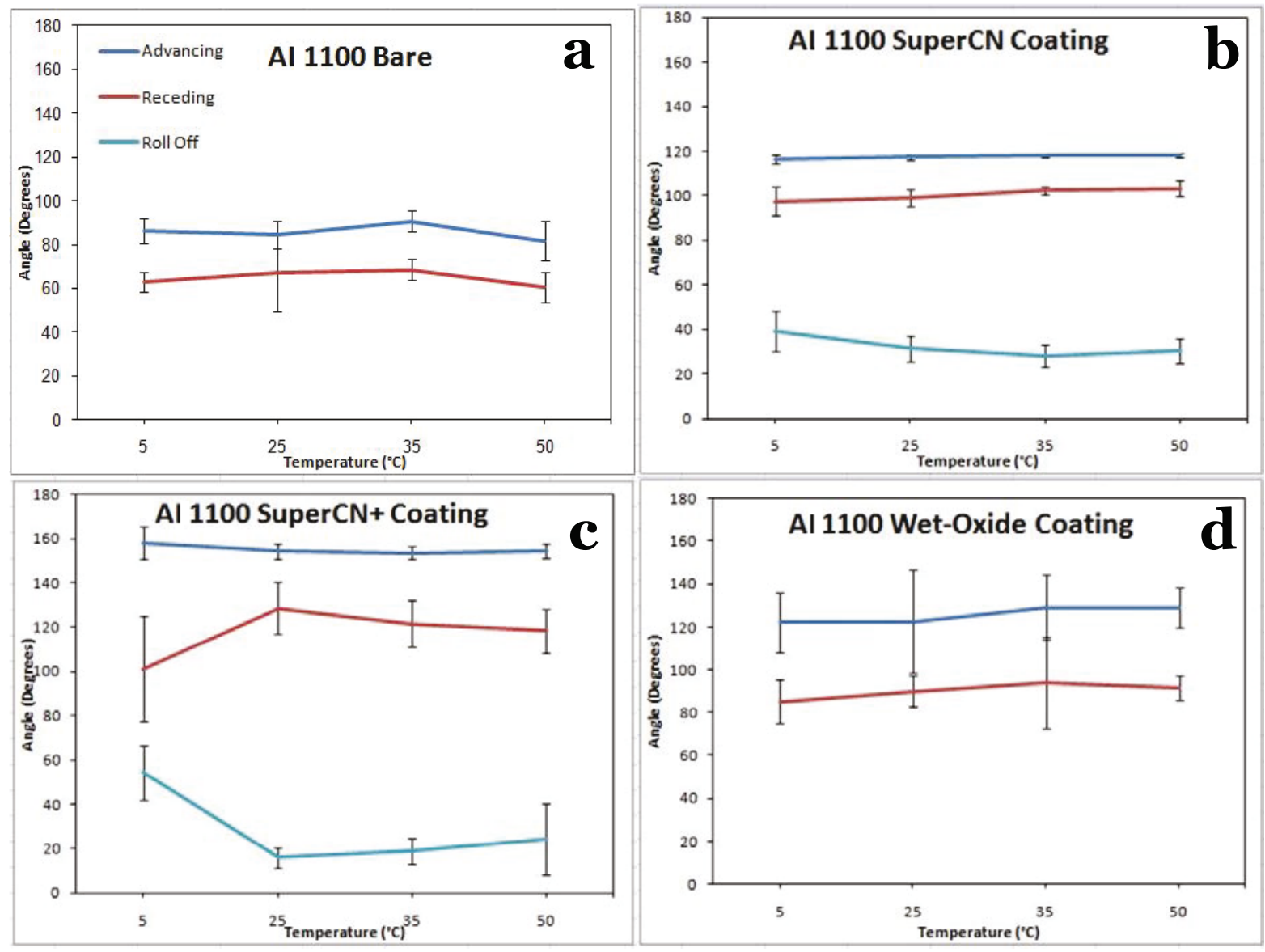




\subsubsection{Coated Al 6061 surfaces}

Similar to the bare $\mathrm{Al} 1100$ coupons, the bare $\mathrm{Al} 6061$ coupons had advancing and receding contact angles that remained around 80 and 60 degrees, respectively, regardless of temperature (Figure 7a). A slight narrowing of the hysteresis was observed as temperature decreased from $25^{\circ} \mathrm{C}$ to $5^{\circ} \mathrm{C}$ with a concomitant increase in the standard deviation. Across all temperatures, the droplets remained adhered to the bare coupons.

The SuperCN coating exhibited similar advancing and receding contact angles (120 and 100, respectively) as when it was on the $\mathrm{Al} 1100$ substrate but with slightly higher roll-off angles (Figure $7 \mathrm{~b}$ ). All values were constant across temperatures, but the roll-off angles had a standard deviation of less than or equal to 20 degrees.

The SuperCN Plus coating on $\mathrm{Al} 6061$ coupons had a 150 degree advancing angle from $50^{\circ} \mathrm{C}$ to $25^{\circ} \mathrm{C}$ that dropped to 140 degrees as temperature was lowered to $5^{\circ} \mathrm{C}$ (Figure $7 \mathrm{c}$ ). The receding angle of SuperCN Plus coatings on $\mathrm{Al} 6061$ decreased from a maximum of 130 degrees at $35^{\circ} \mathrm{C}$ to 110 degrees at $5^{\circ} \mathrm{C}$. This trend resulted in an increased hysteresis at $5^{\circ} \mathrm{C}$. The rolloff angle values remained constant both in average and in standard deviation across all temperatures.

The wet-oxide coating formed on the $\mathrm{Al} 6061$ coupon showed a high standard deviation in all measured values (Figure $7 \mathrm{~d}$ ). The advancing and receding angles remained constant across all temperatures studied, but the rolloff angle showed a 10-degree increase at $5^{\circ} \mathrm{C}$. 
Figure 7. Advancing, receding, and roll-off angles of coatings with an Al 6061 substrate: (a) Al 6061 with no coating applied, (b) Al 6061 with a SuperCN coating applied, (c) Al 6061 with a SuperCN+ coating, and (d) Al 6061 with a wet-oxide coating applied. Note: droplets did not roll from the bare coupons (a) during tilting experiments.
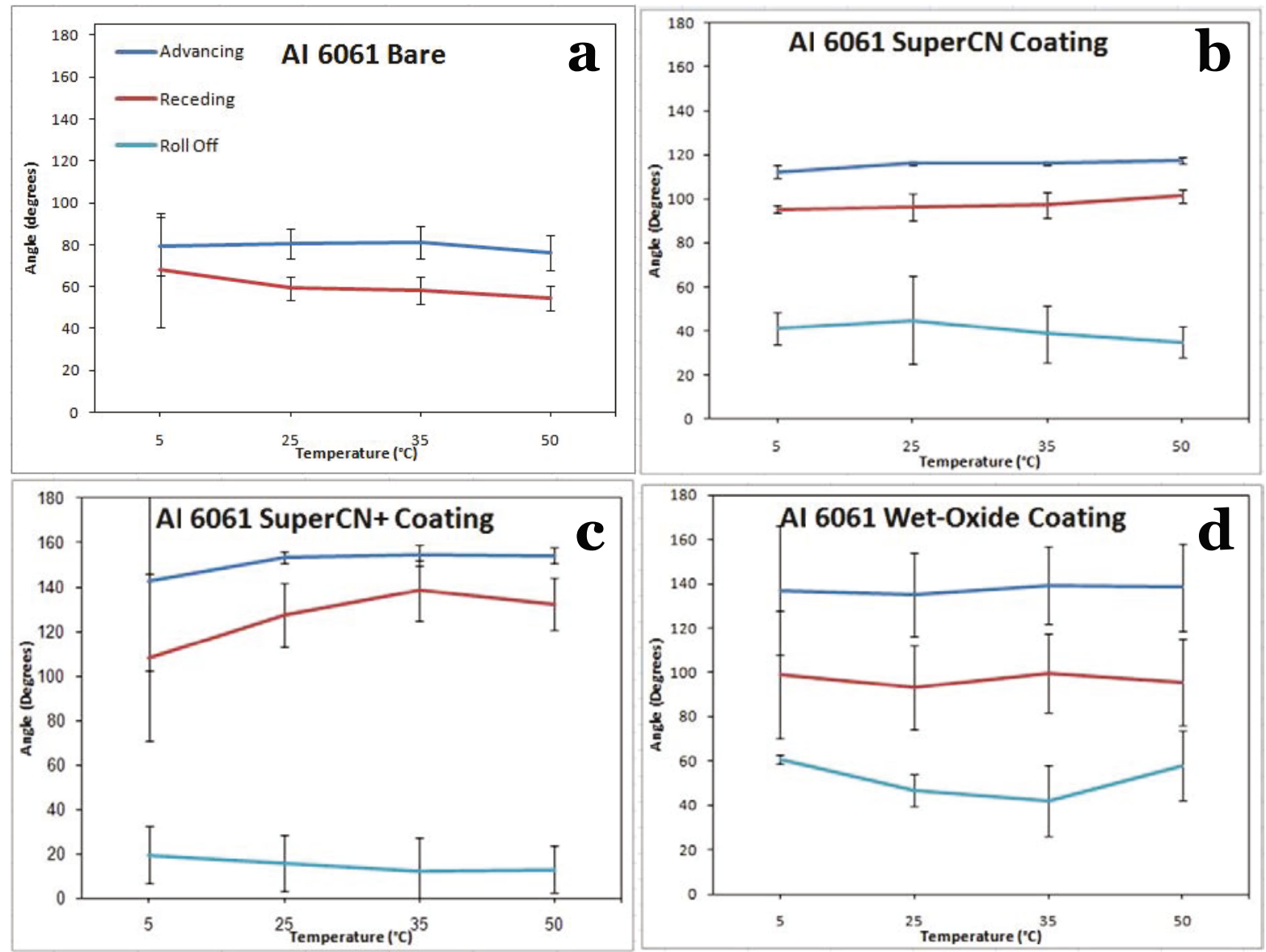

\subsubsection{Coated CDA 101 surfaces}

The bare CDA 101 coupons had advancing and receding contact angles that remained constant at 80 and 60 degrees, respectively, from $50^{\circ} \mathrm{C}$ to $25^{\circ} \mathrm{C}$, maintaining a hysteresis of 20 degrees (Figure 8a). As temperature was lowered from $25^{\circ} \mathrm{C}$ to $5^{\circ} \mathrm{C}$, the advancing angle decrease and the receding angle increased, causing the hysteresis to approach 5 degrees. Regardless of temperature, the droplets remained adhered to the bare CDA 101 coupons.

The SuperCN coating on the CDA 101 coupons had advancing and receding angles that remained at 120 and 100 degrees across all temperatures (Figure 8b). Similar to experiments on the $\mathrm{Al} 1100$ coupons, the SuperCN coating on CDA 101 coupons showed a 20 degrees increase in the roll-off angle as temperature was decreased from $25^{\circ} \mathrm{C}$ to $5^{\circ} \mathrm{C}$. 
The SuperCN Plus coating on the CDA 101 coupons had advancing angles that remained constant at 160 degrees across all temperatures (Figure 8c). The receding angle remained at 130 degrees from $50^{\circ} \mathrm{C}$ to $25^{\circ} \mathrm{C}$ but dropped by 20 degrees when the temperature was lowered to $5^{\circ} \mathrm{C}$, causing an increase in the hysteresis. The roll-off angles for droplets on the SuperCN Plus coating remained at 20 degrees across all temperatures.

On the CDA 101 substrate, the wet-oxide coating had the highest contact angles, the smallest hysteresis, and the lowest roll-off angles (Figure 8d). The advancing and receding contact angles remained at 160 and 140 degrees, respectively, across all temperatures, showing a consistently low hysteresis of 20 degrees. The roll-off angles were consistently below 10 degrees; they were difficult to measure because the droplet adhesion was so low that the droplets were almost repelled from the coating.

Figure 8. Advancing, receding, and roll-off angles of coatings with a CDA 101 substrate: (a) CDA 101 with no coating applied, (b) CDA 101 with a SuperCN coating applied, (c) CDA 101 with a SuperCN+ coating, and (d) CDA 101 with a wet-oxide coating applied. Note: droplets did not roll from the bare coupons (a) during tilting experiments.
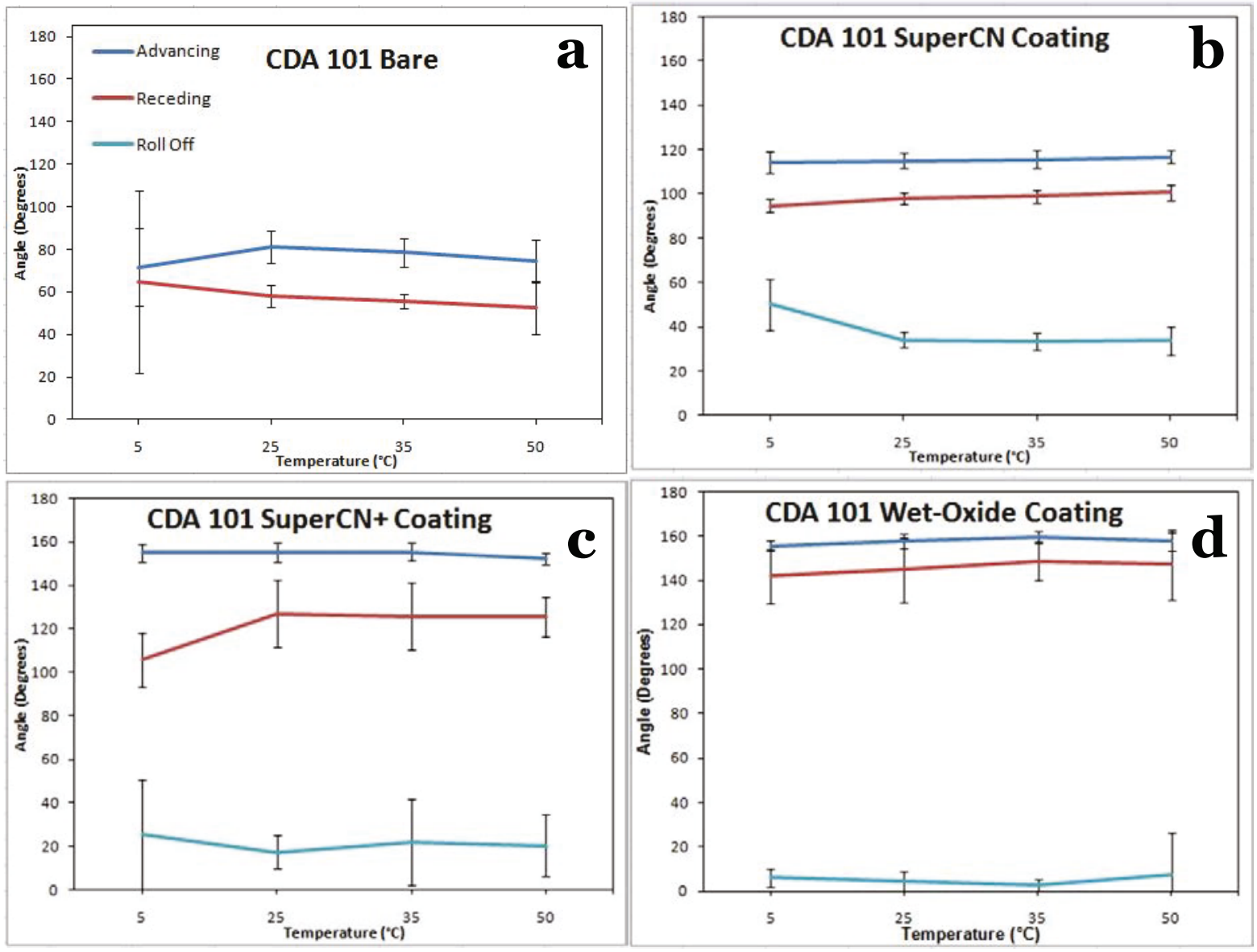


\section{Discussion}

The polymeric coatings showed mostly consistent results regardless of the type of metal coupon to which they were applied. For example, the SuperCN coating consistently demonstrated advancing and receding angles of approximately 120 and 100 degrees, respectively, across all substrates and temperatures. The roll-off angles of the SuperCN coating were consistently 30-40 degrees, only showing a jump to 50 degrees at $5^{\circ} \mathrm{C}$ when on the CDA 101 coupons. The SuperCN Plus coating on the $\mathrm{Al} 100$ coupons and the CD 101 coupons had similar behavior; the receding angle decreased and the roll-off angles increased at $5^{\circ} \mathrm{C}$. The lack of consistency in this trend for the SuperCN Plus coating on the $\mathrm{Al} 6061$ coupons may be a consequence of the lower $\mathrm{Al}$ content (95.9\%-98.6\%) of the $\mathrm{Al} 6061$ alloy.

The changes in wettability occurring near $5^{\circ} \mathrm{C}$ may be caused by changes in the viscosity of the water. The dynamic viscosity of water grows more than threefold from $50^{\circ} \mathrm{C}$ to $5^{\circ} \mathrm{C}$ (Appendix B). This can explain, in part, the increase in roll-off angles and a decrease in receding angles with minimal change to the advancing contact angles. Liquids with higher viscosity have lower wettability, which limits spreading over a surface (Ashokkumar et al. 2012). Because of this, viscosity of the liquid plays a large part in the roll-off angles and dynamic contact angles of the liquids. However, Karmouch and Ross (2010) stated that contact angle and hysteresis changes on PTFE (Teflon) at low temperatures were caused by vapor condensation in the structures of the material.

The wet oxide coatings formed on the three different metal coupons showed very different behavior. Droplets on the $\mathrm{Al} 1100$ oxide coating remained adhered to the coatings through all experiments, the oxide coating on the $\mathrm{Al}$ 6061 coupons had large standard deviations in all values, and the oxide coating on the CDA 101 coupons had consistently high contact angles and negligible roll-off angle.

Overall, the CDA 101 substrate with the wet-oxide coating showed the most promise as a condensation coating. The contact angles stayed very stable with the advancing angle always near 160 degrees and the receding contact angle near 140 degrees. The roll-off angles were consistently below 10 degrees with low standard deviations. Both wettability characteristics indicate 
that droplets on oxide coatings made from copper would have minimal interfacial contact area and low adhesion, allowing them to be harvested for water-resource applications. 


\section{Conclusion}

In this work, we studied the wettability of two different types of coatings, polymeric and oxide, via contact angle goniometry at a variety of temperatures. We measured dynamic contact angle values, hysteresis, and roll-off angle so that these values could be integrated with condensation studies performed in the broader program. By using a temperature chamber, we were able to measure these wettability properties under thermal conditions that would be encountered in a real condensation system.

By far, the most promising surface treatment for condensation was the wet oxide coating, made in-house at CERL, formed on the CDA 101 coupons. The high contact angles, low hysteresis, and negligible roll-off angles imply that droplets formed on these surfaces would have very low adhesion and high collection efficiency. We recommend follow-on work looking at the condensation and collection efficiency of these coatings. 


\section{References}

Ashokkumar, S., J. Adler-Nissen, and P. Møller. 2012. Factors Affecting the Wettability of Different Surface Materials with Vegetable Oil at High Temperatures and Its Relation to Cleanability. Applied Surface Science 263:86-94. doi:10.1016/j.apsusc.2012.09.002.

Cheng, B. K., B. Naccarato, K. J. Kim, A. Kumar. 2016. Theoretical Consideration of Contact Angle Hysteresis Using Surface-Energy-Minimization Methods. International Journal of Heat and Mass Transfer 102:154-161. doi:10.1016/j.ijheatmasstransfer.2016.06.014.

Gao, L., and T. J. McCarthy. 2008. Teflon is Hydrophilic. Comments on Definitions of Hydrophobic, Shear versus Tensile Hydrophobicity, and Wettability Characterization. Langmuir 24 (17): 9183-9188.

Karmouch, R., G. G. Ross. 2010. Experimental Study on the Evolution of Contact Angles with Temperature near the Freezing Point. The Journal of Physical Chemistry C 114 (9): 4063-4066. doi:10.1021/jp911211m

Lee, A., M.-W. Moon, H. Lim, W.-D. Kim, and H.-Y. Kim. 2012. Water Harvest via Dewing. Langmuir 28 (27): 10183-10191.

Li, J., X. Liu, Y. Ye, H. Zhou, and J. Chen. 2011. Fabrication of Superhydrophobic CuO Surfaces with Tunable Water Adhesion. The Journal of Physical Chemistry C 115 (11): 4726-4729.

Murakami, D., H. Jinnai, and A. Takahara. 2014. Wetting Transition from the CassieBaxter State to the Wenzel State on Textured Polymer Surfaces. Langmuir 30 (8): 2061-2067.

Nine, J., T. T. Tung, F. Alotaibi, D. N. H. Tran, D. Losic. 2017. Facile Adhesion-Tuning of Superhydrophobic Surfaces between "Lotus" and "Petal" Effect and Their Influence on Icing and Deicing Properties. Applied Material Interfaces 9:83938402.

Parker, A. R., and C. R. Lawrence. 2001. Water Capture by a Desert Beetle. Nature 414 (6859): 33-34.

Shin, S., J. Seo, H. Han, S. Kang, H. Kim, and T. Lee. 2016. Bio-Inspired Extreme Wetting Surfaces for Biomedical Applications. Materials 9 (2): 116. 


\section{Other Works}

Engineering ToolBox. N.d. Water-Dynamic and Kinematic Viscosity. Engineering Toolbox. https://www.engineeringtoolbox.com/water-dynamic-kinematic-viscosity-d_596.html (accessed 19 December 2016).

Eral, H. B., D. J. C. M. 'T Mannetje, and J. M. Oh. 2012. Contact Angle Hysteresis: A Review of Fundamentals and Applications. Colloid and Polymer Science 291 (2): 247-26o. doi:10.1007/soo396-012-2796-6.

Gilman, J. J. 1960. Direct Measurements of the Surface Energies of Crystals. Journal of Applied Physics 31:2208. doi:10.1063/1.1735524.

Keller, A., V. Broje, and K. Setty. 2007. Effect of Advancing Velocity and Fluid Viscosity on the Dynamic Contact Angle of Petroleum Hydrocarbons. Journal of Petroleum Science and Engineering 58 (1-2): 201-206. doi:10.1016/j.petrol.2006.12.002.

Park, K., P. Kim, A. Grinthal, N. He, D. Fox, J.C. Weaver, and J. Aizenburg. 2016. Condensation on Slippery Asymmetric Bumps. Nature 531:78-82.

Schuster, J. M., C. E. Schvezov, and M. R. Rosenberger. 2015. Analysis of the Results of Surface Free Energy Measurement of Ti6Al4V by Different Methods. Procedia Materials Science 8:732-741.

Sullivan, D. E. 1981. Surface Tension and Contact Angle of a Liquid-Solid Interface. The Journal of Chemical Physics 74 (4): 2604-2615. doi:10.1063/1.441333.

Yuan, Y., and T. R. Lee. 2013. Contact Angle and Wetting Properties. Surface Science Techniques, Springer Series in Surface Sciences 51:3-34. doi:10.1007/978-3642-34243-1_1. 


\section{Appendix A: Standard Operating Procedure for Temperature-Variable Contact Angle Goniometry Measurements}

\section{A.1 Startup}

1. Remove the cover from the contact angle goniometer.

2. Remove the lens cap from the camera.

3. Turn on the backlight, coarse adjust dial to 10 o'clock, and fine adjust from there.

4. Turn on the automated dispensing system.

5. Turn on the tilting base.

6. Turn on the computer.

7. Install the tube into the desiccator. If the desiccant is pink, replace it with fresh desiccant.

8. Turn on the dry air pump attached to the desiccator.

9. Turn on the temperature controller.

10. Check the level below the stage to make sure that the stage is level. If it is not, adjust the legs.

11. Double click on the DROPimage Advanced icon. It will tell you that the dispenser is not initialized and will prompt you to reset it now. Select "Yes," but be ready for water to come out of the end of the needle. Have a receptacle ready for the water.

\section{A.2 Setting up the instrument}

If the experimental set-point temperature is less than room temperature:

1. If the temperature you are testing is below room temperature, using coolant is recommended.

2. Fill a container with ice water. A 5 gal. bucket size is recommended.

3. Attach the clear plastic tube coming from the water pump to the male nozzle on the side of the Peltier stage.

4. Attach the other tube to the other nozzle and have the other end in the container for water to return to. There is a thermistor on this tube. It can be plugged into the temperature controller in the coolant thermocouple spot.

5. Plug in the water pump. 
If the setpoint is greater than $0^{\circ} \mathrm{C}$, set the temperature controller to "Heating." There is a knob for this on the bottom right of the temperature controller. If the set point is less than $0^{\circ} \mathrm{C}$, turn the knob to "Cooling." $\mathbf{o}^{\circ} \mathbf{C}$ to Room Temp $=$ Heating. Temp $<0^{\circ} \mathrm{C}=$ Cooling.

\section{A.3 Preparing the temperature}

1. Go to "Device Control / Temperature Control." Enter the temperature you would like the stage set for under "Set Point" and then select "Set."

2. Once the temperature is within $0.5^{\circ} \mathrm{C}$ of the set point, wait at least 15 minutes before starting an experiment. Preparation can continue before the 15 minutes are up.

\section{A.4 Setting up syringe:}

1. Purge air from the lines by selecting "Device Control / Drop Volume Control." Fill the reservoir by looking on the right side to see how much water is in the syringe. If it is not full in the same window, make sure that the reservoir is selected under the valve box. Then in the syringe level box, select "Fill." Then on the bottom, select " 5 " for the number of rinses, and click rinse. After this, refill the syringe.

2. To prepare for running an experiment, the first step is to set up the syringe. Poke it through the small hole in the rubber stopper while keeping the syringe as straight as possible, and make sure it is within view of the camera.

3. Select "Device Control/Drop Volume Control." On the right side, it is possible to see how much water is in the syringe. If the syringe is not full, make sure that "Reservoir" is selected under the valve box. Then in the "Syringe Level" box, select "Fill." Now make sure that volume step is set to the volume you would like the syringe to output. Under the valve tab, select "Drop." The reservoir button should unselect.

\section{A.5 Depositing the coupon}

1. Make sure the syringe is outside of the Peltier stage. If it is not, use the coarse adjust knob to pull it up.

2. There are three threaded bolts on the top of the Peltier stage. They are higher up than all the other threaded bolts. Loosen all three, and remove the cover they were holding. To remove it, you will need to push it toward the backlight and then pull it up. 
3. Place your coupon in the Peltier stage and replace the cover. Tighten the threaded bolts back into place.

\section{A.6 Setting up the experiment dynamic contact angle measurement with stage tilting and temperature stage}

1. Go to "File/New Experiment Wizard".

2. Select "Contact Angle," and make sure the "With Tilt" box is selected, also. If the "With Tilt" option does not appear, back out and go to "Edit/Options." From there under "Installed options," make sure "Drop Volume Control," "Tilting Base Control," and "Temperature Control” are all selected. When finished, select "OK."

3. Name the file.

4. Select the phases for the test. If the correct options are not available, you can add new ones under "Edit/Edit Phase Data." When done, save and return to step 1. If you would not like to add new ones, you may select any of the ones already available. Be aware that these materials will show up on reports and that incorrect materials will result in inaccurate densities on reports. When finished, select "Next."

5. Under "Total Number of Measurements," enter the number of measurements you would like to be taken over the course of the test. It is recommended to do 181 so that a test will be taken every 0.5 degree if all recommendations are followed for this part.

6. Under "Timing," select "Equidistant," and set a time interval. Note that time interval is the amount of time between measurements.

7. Select the start and end angle. It is recommended to have a start angle of o degrees and an end angle of 90 degrees. This will provide angle steps of 0.5 degrees, meaning a measurement will be taken every 0.5 degrees. When finished, click "Finish."

8. A window will pop up saying, "The Wizard has saved your choices in new Parameter and Method files. Do you want to run this experiment now?" If you are ready to run the experiment select "Yes." However, unless everything is ready, select "No."

\section{A.7 Running an experiment}

1. Focus the camera, and set up the stage where you would like it. You can do this with a sacrificial drop or with the calibration accessory.

2. Go to "Measure/Select Experiment," and select the experiment you would like to run. 
3. Go to the "Drop Volume Control" window, and select "Output Step" (a 10 $\mu \mathrm{L}$ drop is standard) to have the syringe release a drop. Make sure the valve selected is "Drop."

4. Go to "Measure/Start Active Experiment."

5. Three lines should appear on the screen. Two horizontal and one vertical. The red horizontal line should be above the top of the drop but below the syringe. You can move this line by holding Ctrl and clicking at the desired height. The next line is the green horizontal line. This should be at the bottom of the drop so that it does not measure the reflection, also. You can adjust it by holding Shift and clicking. It should be at the smallest point of the base. If the drop is not level, you can adjust it by twisting the knob below the Peltier stage and on the far side from you. If adjusted, return to step 3 to get a more accurate snapshot of the droplet. The final line is the vertical line. It should be at the middle of the drop. You can adjust it by just clicking at the desired location.

6. When finished, click the "Measure" button on the "Set Cursor position" box that popped up when you clicked "Start Active Experiment." The test will now start.

\section{Note: When you click "Measure," a window will pop up full screen with data. Minimize this to see the drop and what it is measuring. If it is a bad run, redo.}

\section{A.8 Collecting/saving data}

Resetting the stage:

When the test is finished, select "Device Control/Tilting Base Control." To return the base to the original position, select "Reset." There is a delay after selecting "Reset."

Viewing the Data:

1. Select "Results/Show Report." The report will pop up.

2. From here, you may save the report as you would any other Microsoft Word file.

Saving the Data:

1. To save the data without viewing it, select "Results/Save Report."

2. Select the location where you would like this data stored. 
Surface Energy:

To save surface energy data, you have to enter it by hand. Under "Tools/Single Liquid Surface Energy (SE)," you can input the mean contact angle (bottom of the results report), and it will output an SE.

\section{A.9 Opening the data in excel}

1. To open the data in Excel, you must first format it correctly.

2. Open the Report file.

3. Select all $(\mathrm{Ctrl}+\mathrm{a})$.

4. Copy $(\mathrm{Ctrl}+\mathrm{c})$.

5. Open a new notepad, and paste it in $(\mathrm{Ctrl}+\mathrm{v})$.

6. Save the notepad so that it can be found later.

7. Open an Excel page that you would like the data put into.

8. Select "Data/From Text." It is in the "Get External Data" box on the left. This may not appear unless Excel is in full screen.

9. Select your file, and click "Import."

10. Make sure that "Delimited" is selected at the top of the first page as well as "Start Import" at row 1. Click "Next" when finished.

11. In the "Delimiters" box, "Tab" should be selected. When finished, select "Finish."

12. A window will pop up called "Import Data." Make sure "Existing Worksheet" is selected, and click "OK."

\section{A.10 Shut down}

1. Make sure the stage is level. You can check this in "Device Control/Tilting Base Control" by selecting "Reset."

2. Shut off the temperature controller.

3. Shut off the dry air pump by unplugging it.

4. Turn off the power strip that the dry air pump and the temperature controller are connected to.

5. Take the tube out of the desiccator. Do this by pushing up on the black part the tube is pushed into and pulling the tube out. It should pull out with ease.

6. Cover the opening on the desiccator with parafilm.

7. Shut off the backlight.

8. Shut off the automated dispensing system.

9. Shut off the tilting base.

10. Shut off the computer. 
11. Put the lens cap on the camera.

12. If coolant was used, unplug the water pump.

13. If coolant was used, remove the clear plastic tube from the Peltier stage. Be gentle with the thermocouple and aware of the fact that these tubes are filled with water. Pour out ice water, and place the pump and the tubes somewhere to dry until next use. If there will not be a next use in the near future, unplug the thermocouple; and put the pump, tubes, and water container away.

14. If necessary, remove the syringe from the Peltier stage, and open the stage top to remove the coupon inside.

15. Place clear plastic cover over the contact angle goniometer. 


\section{Appendix B: Water Viscosity Values}

Table B-1. Water viscosity values as a function of temperature

\begin{tabular}{|c|c|}
\hline Temperature $\left({ }^{\circ} \mathrm{C}\right)$ & Dynamic Viscosity $\left(\mathrm{N} \mathrm{s} / \mathrm{m}^{2}\right)$ \\
\hline 0 & 1.787 \\
\hline 5 & 1.519 \\
\hline 10 & 1.307 \\
\hline 20 & 1.002 \\
\hline 30 & 0.798 \\
\hline 40 & 0.653 \\
\hline 50 & 0.547 \\
\hline 60 & 0.467 \\
\hline 70 & 0.404 \\
\hline 80 & 0.355 \\
\hline 90 & 0.315 \\
\hline 100 & 0.282 \\
\hline
\end{tabular}




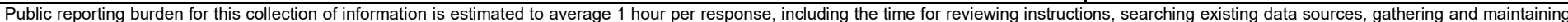

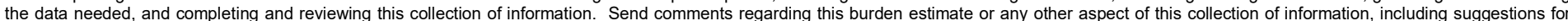

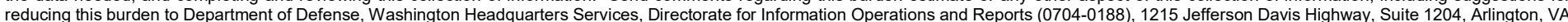

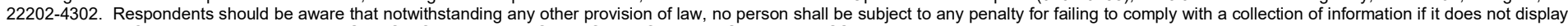
a currently valid OMB control number. PLEASE DO NOT RETURN YOUR FORM TO THE ABOVE ADDRESS.
1. REPORT DATE (DD-MM-YYYY)
2. REPORT TYPE
February 2018
Technical Report/Final

\section{TITLE AND SUBTITLE}

Surface Wettability Using Contact Angle Goniometry

3. DATES COVERED (From - To)

5a. CONTRACT NUMBER

5b. GRANT NUMBER

5c. PROGRAM ELEMENT NUMBER

622720048

6. AUTHOR(S)

5d. PROJECT NUMBER

Jack Heller and Emily Asenath-Smith

5e. TASK NUMBER

5f. WORK UNIT NUMBER

7. PERFORMING ORGANIZATION NAME(S) AND ADDRESS(ES)

8. PERFORMING ORGANIZATION REPORT NUMBER

U.S. Army Engineer Research and Development Center (ERDC)

Cold Regions Research and Engineering Laboratory (CRREL)

ERDC/CRREL TR-18-1

72 Lyme Road

Hanover, NH $03755-1290$

9. SPONSORING / MONITORING AGENCY NAME(S) AND ADDRESS(ES)

Assistant Secretary of the Army for Acquisition, Logistics and Technology

103 Army Pentagon

Washington, DC 20314-1000

10. SPONSOR/MONITOR'S ACRONYM(S)

ASA(ALT)

11. SPONSOR/MONITOR'S REPORT NUMBER(S)

\section{DISTRIBUTION / AVAILABILITY STATEMENT}

Approved for public release; distribution is unlimited.

\section{SUPPLEMENTARY NOTES}

ERDC 6.2 Advanced Low Logistics Water (ALL-H2O)

\section{ABSTRACT}

This study measured surface wettability on a variety of coatings at various temperatures to assess the capacity of the coatings to facilitate water condensation for water collection from vapor. Both commercial polymeric coatings and oxide coatings made in house were selected based on their published hydrophobicity, and aluminum and copper coupons were used as substrates. Dynamic contact angle measurements were performed over the temperature range $5^{\circ} \mathrm{C}-50^{\circ} \mathrm{C}$ with an automated, tilting-stage, contact angle goniometer equipped with a Peltier environmental chamber for temperature control. While the commercial polymeric coatings exhibited consistent (super) hydrophobic wettability across all substrates, the roll-off angles were greater than 20 degrees. The most promising candidate was the wet-oxide coating formed on copper substrates. The high contact angles, low hysteresis, and negligible roll-off angles imply that droplets formed on these surfaces would have very low adhesion and high collection efficiency.

\section{SUBJECT TERMS}

Adhesion, Coatings, Condensation, Contact Angle Goniometry, Hydrophobic surfaces, Materials, Surface chemistry, Oxide, Water harvesting, Wettability

\section{SECURITY CLASSIFICATION OF:}

\section{a. REPORT}

Unclassified

\section{b. ABSTRACT}

Unclassified

\section{c. THIS PAGE}

Unclassified

\begin{tabular}{|c|c|}
\begin{tabular}{c|} 
17. LIMITATION \\
OF ABSTRACT
\end{tabular} & $\begin{array}{c}\text { 18. NUMBER } \\
\text { OF PAGES }\end{array}$ \\
\cline { 2 - 2 } & 34 \\
\cline { 3 - 3 } &
\end{tabular}

19a. NAME OF RESPONSIBLE PERSON

19b. TELEPHONE NUMBER (include area code) 